\title{
Corynebacterium diphtheriae bv. mitis
}

National Cancer Institute

\section{Source}

National Cancer Institute. Corynebacterium diphtheriae bv. mitis. NCI Thesaurus. Code C122272.

A biovar of Corynebacterium diphtheriae. Biovar mitis is nitrate positive and positive for fermentation of glucose and maltose. 